04

\title{
Динамика импульсного магнетронного разряда в сильноточной электронной пушке
}

\author{
(С) П.П. Кизириди, ${ }^{1}$ Г.Е. Озур, ${ }^{1}$ Л.А. Зюлькова, ${ }^{1}$ С.А. Попов, ${ }^{1}$ С.А. Шевелёв, ${ }^{2}$ М.А. Алёхин ${ }^{1,2}$ \\ ${ }^{1}$ Институт сильноточной электроники СО РАН, \\ 634055 Томск, Россия \\ ${ }^{2}$ Национальный исследовательский Томский политехнический университет, \\ 634050 Томск, Россия \\ e-mail: kiziridi_pavel@mail.ru
}

(Поступило в Редакцию 22 февраля 2017 г.)

С помощью скоростной видеосъемки исследована динамика импульсного газового разряда низкого давления (аргон $0.053-0.133 \mathrm{~Pa}$ ) в планарном магнетроне, встроенном во взрывоэмиссионный катод сильноточной электронной пушки. Установлено, что вначале разряд зажигается у боковой поверхности катода и лишь затем переходит на его торцевую поверхность. Исследована зависимость стабильности момента зажигания разряда на торцевой поверхности катода от давления рабочего газа и конструкции катода. Установлено, что наложение импульсного продольного магнитного поля приводит к переключению разряда в аксиальном направлении на коллектор электронной пушки. Представлено качественное объяснение наблюдаемого поведения разряда.

DOI: 10.21883/JTF.2017.11.45123.2217

\section{Введение}

Источники нерелятивистских $(10-30 \mathrm{keV})$ сильноточных (10-25 kA) импульсных $(2-4 \mu \mathrm{s})$ электронных пучков (НСЭП) со взрывоэмиссионным катодом и плазменным анодом на основе сильноточного отражательного (пеннинговского) разряда (ОР) представляют большой интерес для поверхностной обработки материалов и уже нашли достаточно широкое применение [1-4]. В то же время ряд вопросов их формирования и транспортировки изучен пока недостаточно, несмотря на то что исследованию физики и техники сильноточных электронных пучков посвящено огромное количество оригинальных работ и целый ряд монографий [5-7]. К числу малоизученных вопросов физики и техники НСЭП следует отнести проблему однородности распределения плотности тока (энергии) пучка по его поперечному сечению, которая является одной из ключевых с точки зрения поверхностной обработки материалов [3,8-11], особенно при решении задач, связанных с формированием поверхностных сплавов из предварительно нанесенных покрытий [12].

Суть проблемы однородности сильноточных электронных пучков заключается в следующем. Плотности тока электронов и ионов в двойном слое, в котором формируется электронный пучок, связаны между собой соотношением Ленгмюра: $j_{e}=j_{i}(M / m)^{1 / 2}$, где $M$ и $m-$ массы иона и электрона соответственно. На первый взгляд для обеспечения однородности плотности тока НСЭП, $j_{e}(r)$, необходима соответствующая однородность распределения плотности ионного тока, $j_{i}(r)$, по сечению плазменного анода. Однако исследования и опыт эксплуатации сильноточных электронных пушек показали, что при однородном распределении $j_{i}(r)$ рас- пределение плотности энергии пучка на мишени тем не менее имеет ярко выраженный максимум в центральной части $[8,10]$. Одной из причин такой трансформации электронного пучка в процессе транспортировки в плазменном канале является накопление ионов плазмы в приосевой области пучка под действием его собственного радиального электрического поля, появляющегося на стадии нарастания тока вследствие запаздывания зарядовой нейтрализации [6]. Дополнительный вклад в увеличение плотности энергии в центральной области пучка обусловлен действием его собственного магнитного поля, которое сравнимо по величине с ведущим магнитным полем (0.15-0.25 T).

Для компенсации этого негативного эффекта „фокусировки“ НСЭП необходимо создать плазменный анод с увеличенной на периферии концентрацией ионов $n_{i}(r)$. В [10] для этой цели использовались дуговые источники плазмы, встроенные в анод ОР и обеспечивающие усиление ионизации рабочего газа преимущественно на периферии плазменного анода. В данной системе удалось улучшить однородность пучка, но несколько ухудшилась стабильность его параметров, обусловленная, видимо, нестабильностью срабатывания дуговых источников.

В [13] нами была предложена другая идея формирования усиленного на периферии профиля $n_{i}(r)$, заключающаяся в установке во взрывоэмиссионный катод планарного магнетрона. Магнетрон генерирует кольцевое облако плазмы вблизи катода и поток нейтралов, образующихся при катодном распылении. Поэтому при последующем зажигании сильноточного ОР, формирующего плазменный анод, можно ожидать усиления плотности ионного тока на его периферии по сравнению с центральной частью. По сравнению с [10] предлагаемый способ выглядит более перспективным. Кроме того, 
предварительное создание плазмы на взрывоэмиссионном катоде с помощью планарного магнетрона должно улучшить стабильность эмиссии катода. Предварительные испытания сильноточной электронной пушки нового класса, в которой плазменный анод создается с помощью гибридного разряда, сочетающего импульсные магнетронный разряд (MP) и ОР, показали ее работоспособность [13].

Однако для понимания процессов в такой пушке необходимо исследовать динамику импульсного МР, его пространственно-временны́е характеристики. Такого рода данные в литературе практически отсутствуют, поскольку МР, используемый, прежде всего, в технологиях напыления покрытий, функционирует в непрерывном или импульсно-периодическом режиме $[14,15]$ и изучается именно с точки зрения построения и использования напылительных установок или ионных источников. Устройство, сочетающее планарный магнетрон с пеннинговской разрядной ячейкой, описанное в [16], также использовалось для нанесения покрытий в стационарном режиме. Таким образом, исследование динамики импульсного МР и оценка перспективности его использования для формирования плазменного анода сильноточной электронной пушки представляются актуальными.

\section{1. Экспериментальная установка и методики измерений}

На рис. 1 схематично представлена созданная нами электронная пушка „ВЭКсМА“ (ВзрывоЭмиссионный Катод с МАгнетроном), на которой проводились эксперименты. Внутренний диаметр корпуса пушки составляет $204 \mathrm{~mm}$. Электродная система пушки включает в себя катодный узел 3, кольцевой анод ОР 5 и коллектор. В экспериментах по скоростной видеосъемке свечения плазмы разряда коллектором являлась сетка 10 из нержавеющей стали с ячеей $2 \times 2 \mathrm{~mm}$ и геометрической

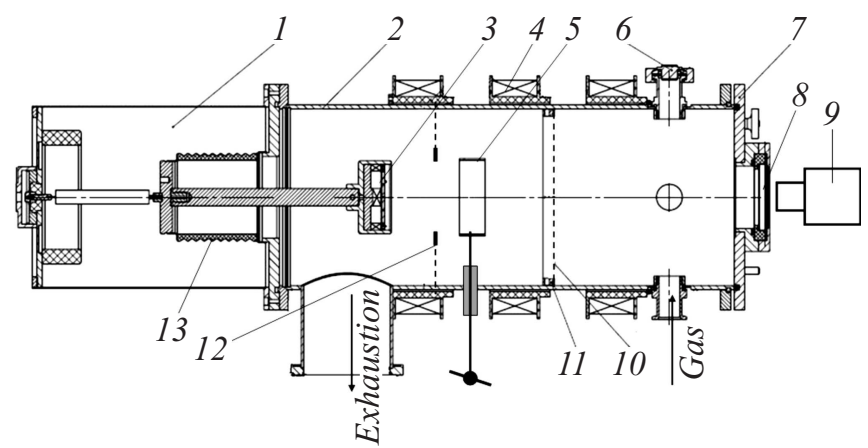

Рис. 1. Схема экспериментальной установки: 1 - катодный ввод, 2 - корпус пушки, 3 - катодный узел, $4-$ соленоид, 5 - анод ОР, 6 - патрубок для установки датчика вакуума, 7 - фланец, 8 - оптическое окно, 9 - скоростная видеокамеpa Photron Fastcam SA1.1, 10 - сетка, 11 - опорное кольцо, 12 - диафрагма с сеткой, 13 - высоковольтный изолятор.

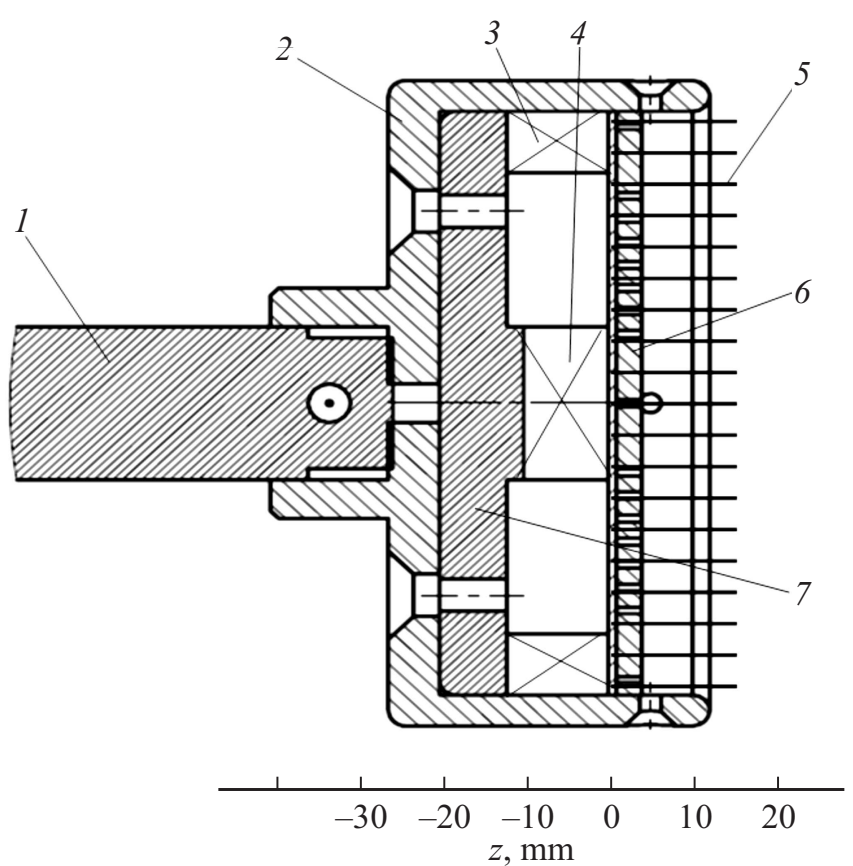

Рис. 2. Сборочный чертеж катодного узла. 1 - катододержатель, 2 - обойма, 3 - кольцевой постоянный магнит $\varnothing 76 \times \varnothing 60 \times 12$ (материал $\mathrm{Nd}-\mathrm{Fe}-\mathrm{B}), 4$ - дисковый постоянный магнит $\varnothing 20 \times 10$ (материал $\mathrm{Nd}-\mathrm{Fe}-\mathrm{B}$ ), 5 - эмиттер, 6 - подложка, 7 - магнитопровод.

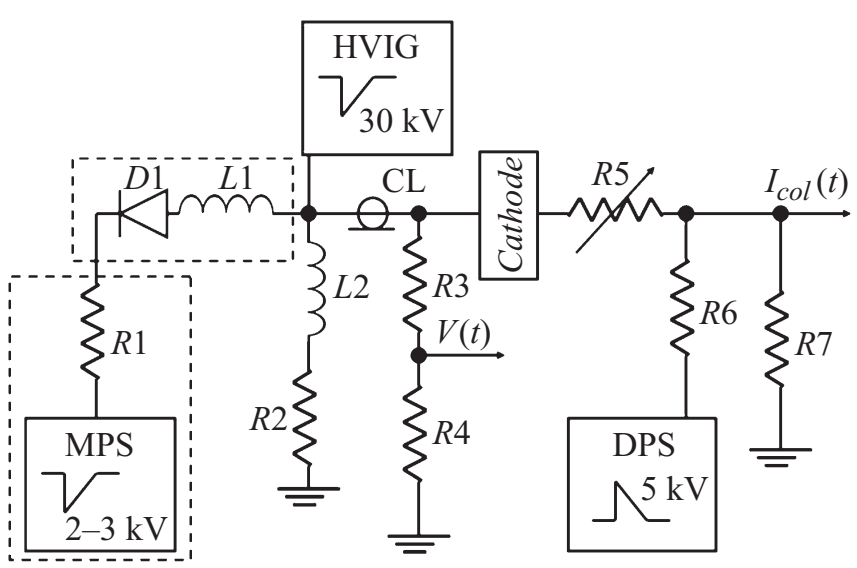

Рис. 3. Принципиальная электрическая схема. $L 1 \approx 100 \mu \mathrm{H}$; $L 2 \approx 140 \mu \mathrm{H} ; \quad R 1=500 \Omega ; R 2=1.1 \mathrm{k} \Omega ; R 3=4.4 \mathrm{k} \Omega ; R 4=$ $=2.2 \Omega ; R 5-$ сопротивление магнетронного разряда; $R 6=30 \Omega ; R 7=1 \Omega$ (шунт); $D 1-$ линейка диодов HER 308 на $45 \mathrm{kV}$, MPS - блок питания магнетрона; DPS - блок питания отражательного разряда; CL - передающая линия. HVIG - генератор высоковольтных импульсов.

прозрачностью около 80\%. Видеосъемка осуществлялась с помощью цифровой скоростной камеры Photron FastCam SA1.1 при скорости записи 12000 кадров в секунду. Камера была синхронизована с моментом начала разряда с точностью не хуже $\pm 1 \mu \mathrm{s}$.

Откачка объема пушки до давления около $3 \times 10^{-3} \mathrm{~Pa}$ осуществлялась турбомолекулярным насосом OSAKA 

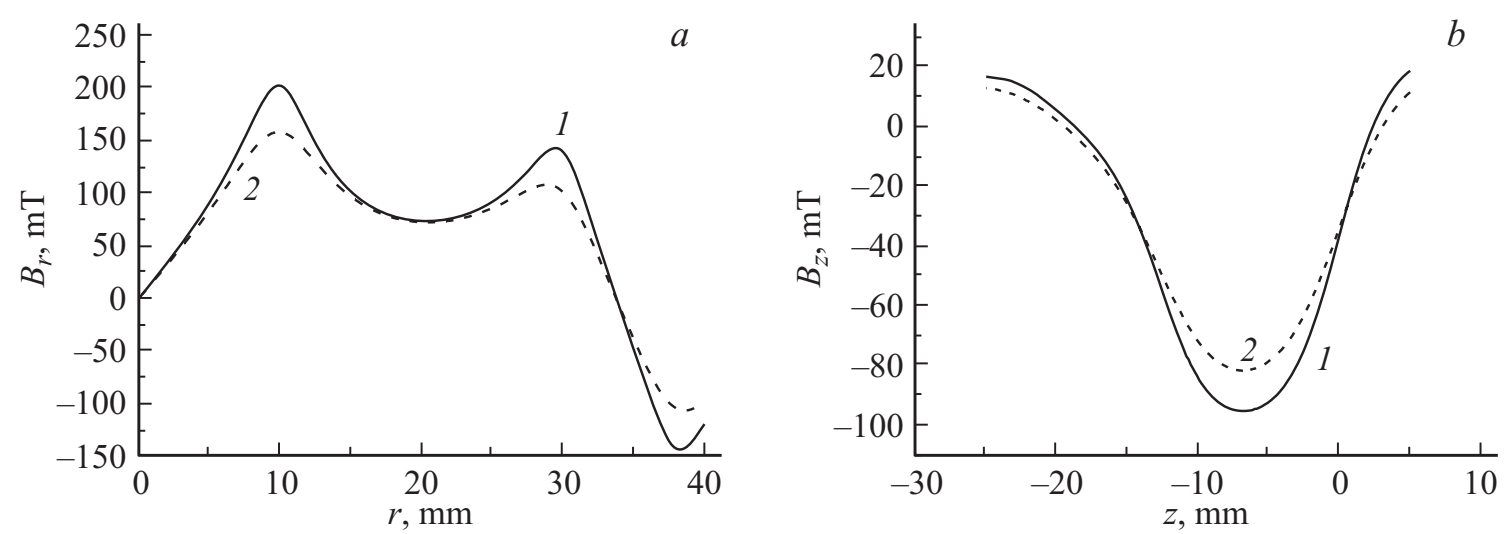

Рис. 4. Распределения магнитной индукции: $a-B_{r}(r)$ при $a=0$ (кривая 1$)$ и $1 \mathrm{~mm}($ кривая 2$) ; b-B_{z}(z)$ при $b=4$ (кривая 1$)$ и $5 \mathrm{~mm}$ (кривая 2). $a$ - расстояние от плоскости катодной подложки; $b$ - расстояние от наружной боковой поверхности кольцевого магнита. $b=4 \mathrm{~mm}$ соответствует наружной боковой поверхности обоймы, $b=5 \mathrm{~mm}$ соответствует расстоянию $1 \mathrm{~mm}$ от этой поверхности. Координата $r$ отсчитывается от оси системы, привязка координаты $z$ к катоду указана на рис. 2.

(2401/s). Напуск рабочего газа (аргона) осуществлялся стационарно с помощью прибора СНА-2.

При проведении части электрических измерений видеокамера удалялась, а вместо окна устанавливался коллекторный узел, заземленный через шунт $(1 \Omega)$. Диаметр коллектора (нержавеющая сталь) составлял $120 \mathrm{~mm}$.

Конструкция катодного узла приведена на рис. 2. В качестве эмиттеров служили медные проволочки $\varnothing 1 \mathrm{~mm}$, запрессованные, а затем распаянные с тыльной стороны подложки из нержавеющей стали толщиной $2 \mathrm{~mm}$ и диаметром $76 \mathrm{~mm}$. Магнетрон и подложка с эмиттерами помещены в обойму 2 из нержавеющей стали наружным диаметром $84 \mathrm{~mm}$. Эмитирующая часть катодного узла изготовлена в двух экземплярах. В первом случае высота эмиттеров составляет $15 \mathrm{~mm}$, шаг (межцентровое расстояние) между эмиттерами $-3 \mathrm{~mm}$, общее число эмиттеров - 514. Во втором случае высота эмиттеров составляет $10 \mathrm{~mm}$, шаг между эмиттерами $-5 \mathrm{~mm}$, общее число эмиттеров - 189. В ряде экспериментов использовался в качестве модельного и чисто плоский катод.

Магнитная система магнетрона образована кольцевым постоянным магнитом 3, дисковым постоянным магнитом 4 и магнитопроводом 7 , изготовленным из углеродистой стали. Система создает над поверхностью катода кольцевое арочное магнитное поле, которое обеспечивает замкнутый азимутальный дрейф электронов, что, в свою очередь, обеспечивает зажигание МР при низких давлениях рабочего газа (обычно около $0.2 \mathrm{~Pa}$ ).

Продольное (ведущее для электронов пучка) импульсное магнитное поле создавалось соленоидом 4, питаемым от конденсаторной батареи через тиристорный ключ. Время нарастания тока соленоида до максимума составляло $5.5 \mathrm{~ms}$.

Важным вопросом работоспособности представленной схемы электронной пушки является различие давлений рабочего газа (аргона), при которых зажигается МР и генерируется сильноточный электронный пучок.
Для зажигания MP обычно требуется давление $0.2 \mathrm{~Pa} \mathrm{и}$ выше (при амплитуде поджигающего импульса $0.8-1 \mathrm{kV}$ и индукции магнитного поля на поверхности катода 0.05-0.06 T). Для генерации же НСЭП оптимальным является давление примерно втрое меньшее, и это различие представляло дополнительную проблему, требовавшую решения.

Принципиальная электрическая схема экспериментов представлена на рис. 3. Блок питания магнетрона (БПМ) формирует импульс длительностью до $20 \mathrm{~ms}$ путем разряда емкостного накопителя $(20 \mu \mathrm{F})$, заряженного до $0.5-3 \mathrm{kV}$, через балластный резистор $R 1$. Внутри БПМ расположены датчики выходного напряжения и полного тока БПМ (на схеме не показаны). Линейка диодов $D 1$ служит для защиты БПМ от перенапряжения при подаче импульса ускоряющего напряжения на катод; резистор $R 2$ и катушка индуктивности $L 2$ обеспечивают при этом развязку катода от „земли“ при подаче на него ускоряющего напряжения от генератора высоковольтных импульсов (ГВИ). Вследствие деления напряжения на резисторах $R 1$ и $R 2$ (с учетом параллельного ему сопротивления $R 3$ ) на катод подается примерно $2 / 3$ зарядного напряжения БПМ.

Блок питания отражательного разряда (БПР) работает аналогично БПМ. Отличие заключается в величине накопительной емкости $(1 \mu \mathrm{F})$, зарядное напряжение составляет $5 \mathrm{kV}$, а сопротивление балластного резистоpa $R 6$ составляет $30 \Omega$. Таким образом, длительность импульса БПР составляет около $100 \mu \mathrm{s}$, а амплитуда тока достигает $150 \mathrm{~A}$.

Сигналы с датчиков тока и напряжения подавались на входы цифрового осциллографа Tektronix TDS 2024 с полосой пропускания $200 \mathrm{MHz}$.

Синхронизация всех импульсных блоков питания осуществлялась с помощью 6-канального генератора импульсов с оптоволоконной развязкой, созданного в ИСЭ СО РАН группой В.Н. Киселёва. 


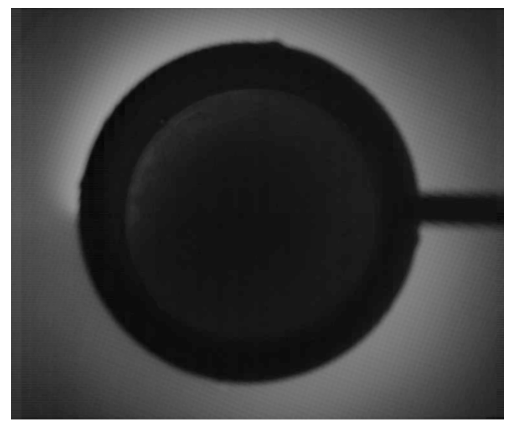

$0.750-0.833 \mathrm{~ms}$

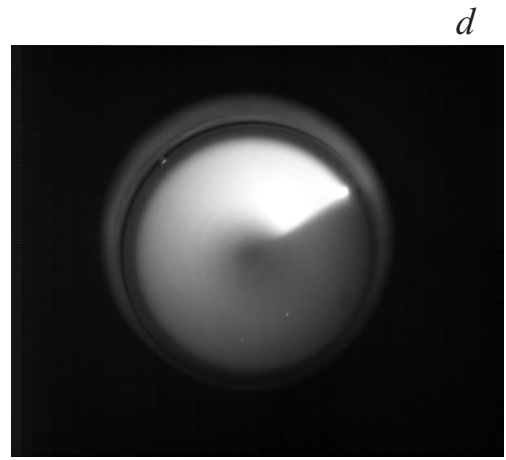

$10.501-10.584 \mathrm{~ms}$ $b$

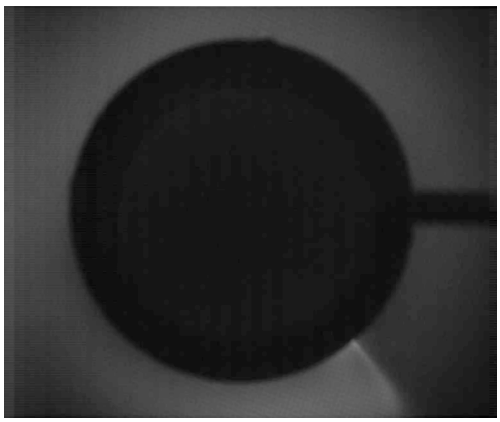

$1.418-1.501 \mathrm{~ms}$

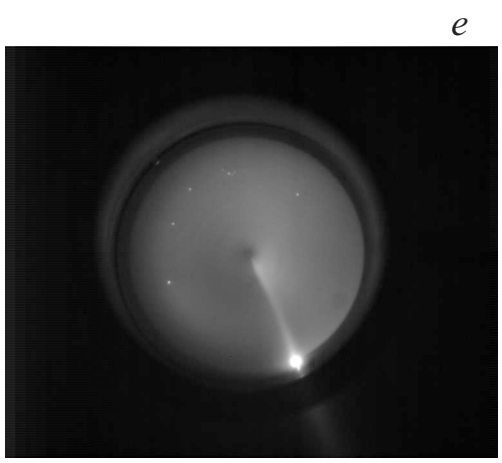

$10.418-10.5 \mathrm{~ms}$

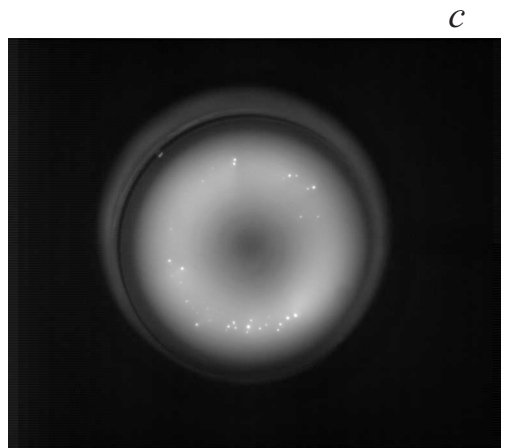

$9.334-9.417 \mathrm{~ms}$

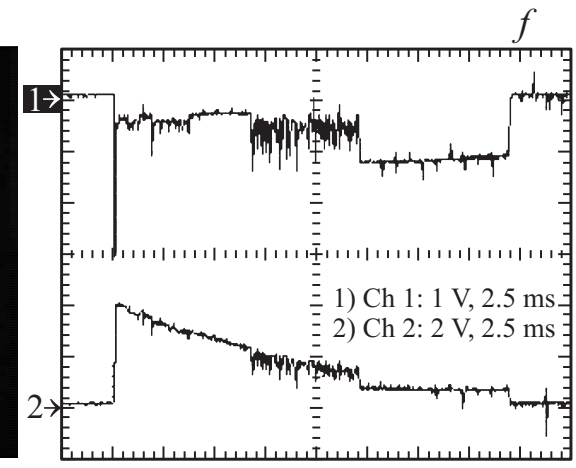

Рис. 5. Кадры видеосъемки $(a)-(e)$ и соответствующие осциллограммы $(f)$ напряжения горения разряда $(\mathrm{Ch} 1,400 \mathrm{~V} / \mathrm{div})$ и полного тока БПМ (Ch2, $2 \mathrm{~A} / \mathrm{div})$; горизонтальная шкала $2.5 \mathrm{~ms} / \mathrm{div}$. Давление аргона 0.067 Ра, зарядное напряжение БПМ $2 \mathrm{kV}$.

\section{2. Результаты}

\section{1. Расчеты магнитного поля}

Нами были проведены расчеты магнитного поля магнетрона с помощью программы COMSOL Multiphysics. При этом нас интересовали, прежде всего, компоненты магнитного поля, поперечные электрическому, т.е. радиальная компонента $B_{r}$ в плоскостях, параллельных катодной подложке, и аксиальная компонента $B_{z}$ в окружностях, параллельных боковой поверхности катодной обоймы. Результаты расчетов, некоторые из которых приведены на рис. 4, были в дальнейшем использованы в анализе результатов скоростной видеосъемки. Проверка расчетов была осуществлена с помощью измерителя магнитной индукции РШ1-10 и подтвердила их правильность.

На рис. 4, $a$ представлено распределение $B_{r}$ вдоль поверхности катода $(a=0)$ и на расстоянии $1 \mathrm{~mm}$ от катода $(a=1 \mathrm{~mm})$. На рис. $4, b$ представлено распределение $B_{z}$ на расстояниях $b$ от боковой поверхности кольцевого магнита, равных 4 и $5 \mathrm{~mm}$.

\section{2. Видеосъемка свечения разряда}

Нами проведен цикл исследований свечения импульсного МР в различных условиях для трех типов катода и четырех значений давления рабочего газа: 0.053, $0.067,0.093$ и $0.133 \mathrm{~Pa}$. Кроме того, изучались случаи с наложением импульсного продольного магнитного поля соленоида и включением ОР. В каждом режиме производилось 5 „выстрелов“ и соответственно регистрировалось 5 видеофайлов. Одновременно регистрировались осциллограммы напряжения горения МР и полного тока БПМ.

\subsection{1. Плоский катод}

На рис. 5 приведены результаты видеосъемки, полученные для случая плоского катода, служившего модельным объектом. Анализ полученных данных показал следующее.

1. Вначале появляется свечение вблизи боковой поверхности катодного узла и вообще в радиальном зазоре между ним и стенкой. Время до появления этого свечения составляет $0.4-0.7 \mathrm{~ms}$ при давлении аргона $p=0.053$ Ра и уменьшается до 0.07-0.15 ms при давлении аргона $p=0.067$ Ра и выше. Появление этого свечения совпадает с ростом тока и соответствующим спадом напряжения разряда до 100-250 V. Продолжительность этой стадии составляет обычно несколько $\mathrm{ms}$, причем интенсивность свечения может и сильно падать, а могут и появляться яркие радиальные каналы (рис. 5, $a$ и $b$ ).

2. Через 5.5-9.5 ms (в зависимости от давления аргона) появляется свечение на торцевой поверхности катода, т.е. там, где нам и нужно (рис. 5,c). Свечение имеет ожидаемую кольцевую структуру, характерную для традиционного планарного магнетрона. На фоне 


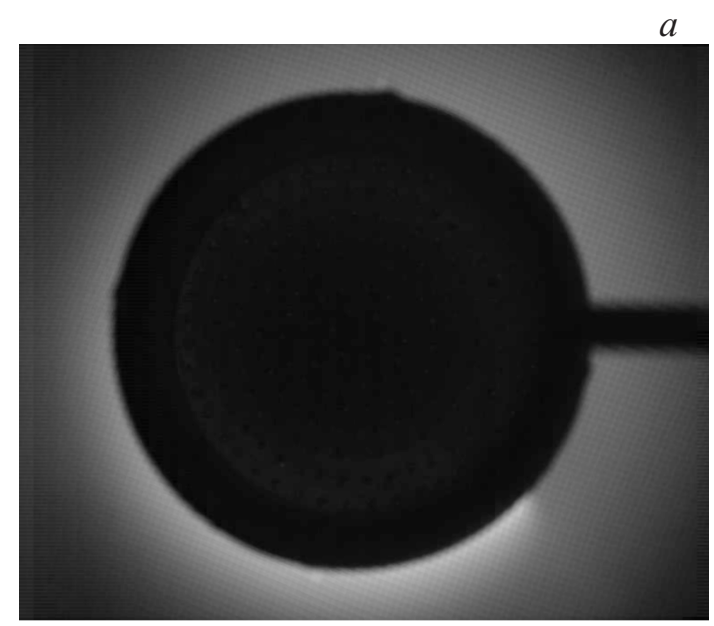

$0.251-0.334 \mathrm{~ms}$

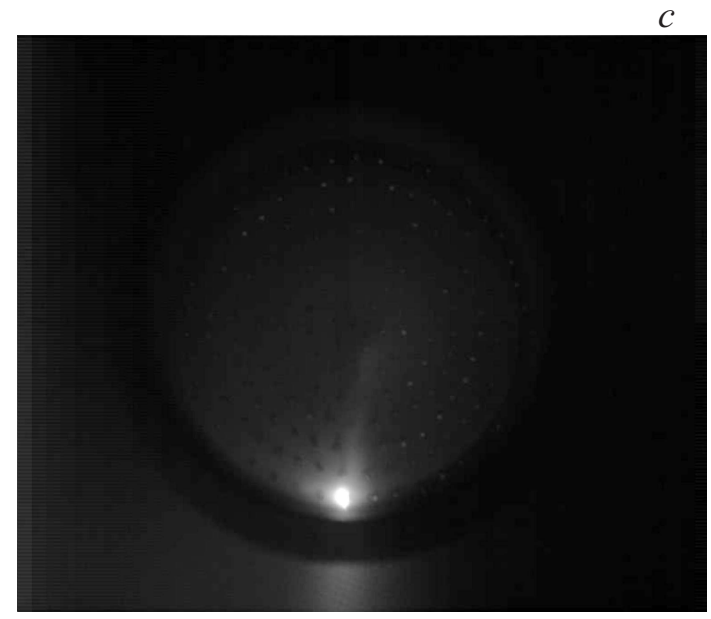

$5.251-5.333 \mathrm{~ms}$

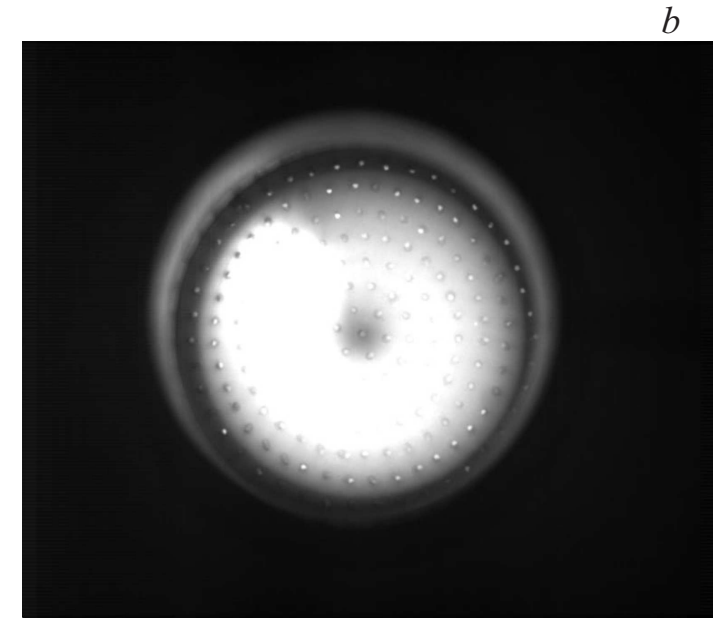

$1.084-1.167 \mathrm{~ms}$

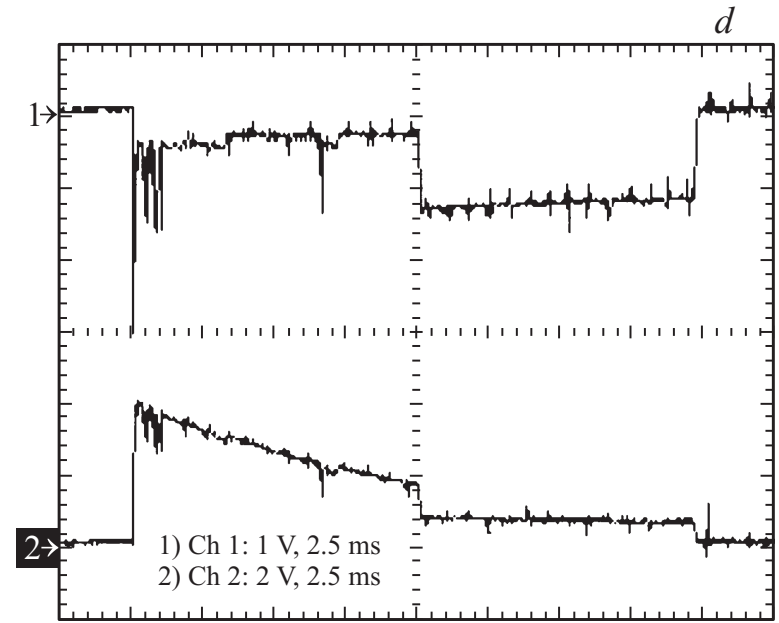

Рис. 6. Кадры видеосъемки $(a)-(c)$ и соответствующие осциллограммы $(d)$ напряжения горения разряда (Ch1, $400 \mathrm{~V} / \mathrm{div})$ и полного тока БПМ (Ch2, $2 \mathrm{~A} / \mathrm{div})$; горизонтальная шкала $2.5 \mathrm{~ms} / \mathrm{div}$. Давление аргона $0.067 \mathrm{~Pa}$, зарядное напряжение БПМ $2 \mathrm{kV}$.

диффузного свечения наблюдаются яркие пятна. Видимо, это катодные пятна, а их сравнительно большое количество на снимке (до двух десятков) обусловлено большой длительностью единичного кадра $(83.3 \mu \mathrm{s})$, существенно превосходящей время жизни катодного пятна с током, близким к пороговому (около 1А), которое составляет доли микросекунд. Таким образом, наблюдаемое свечение представляет интегрированную по длительности кадра картину, а число одновременно существующих катодных пятен составляет единицы.

Момент начала данного свечения достаточно стабилен от импульса к импульсу. Продолжительность этой стадии в среднем 1-1.5 ms. Затем свечение становится более неоднородным, ток падает, а напряжение горения возрастает до 500-600 V, характерных для тлеющего разряда.

\subsection{2. Катод с шагом $5 \mathrm{~mm}$ между проволочны- ми эмиттерами}

Динамика свечения для данного катода близка к случаю плоского катода, однако время до появления свечения на торцевой поверхности резко сократилось, примерно до $1 \mathrm{~ms}$ (рис. 6).

Появлению свечения на торцевой поверхности катода, как правило, предшествует кратковременный скачок напряжения до 500-600 V. Момент начала данного свечения достаточно стабилен от импульса к импульсу. Завершается процесс горения разряда на торцевой поверхности катода через $2-3 \mathrm{~ms}$ появлением одиночного яркого катодного пятна (рис. 6,c). Напряжение горения разряда при этом составляет около 100-120 V. Через 9.5-11 ms после начала импульса все гаснет.

\subsection{3. Катод с шагом $3 \mathrm{~mm}$ между проволочны- ми эмиттерами}

Уменьшение расстояния между эмиттерами с 5 до $3 \mathrm{~mm}$ резко отрицательно сказывается на стабильности появления кольцевого свечения на плоскости катода. Поэтому данный случай мы детально рассматривать не будем; отметим только этот факт нестабильности. 


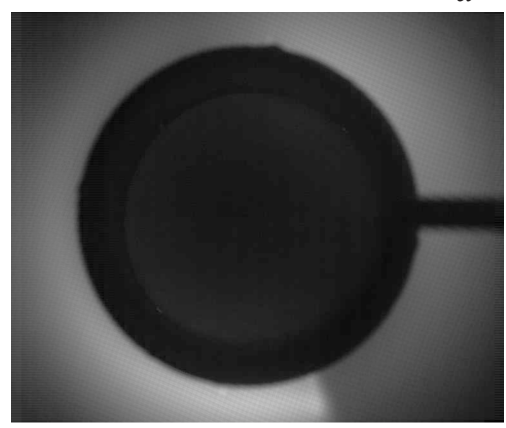

$2.168-2.251 \mathrm{~ms}$

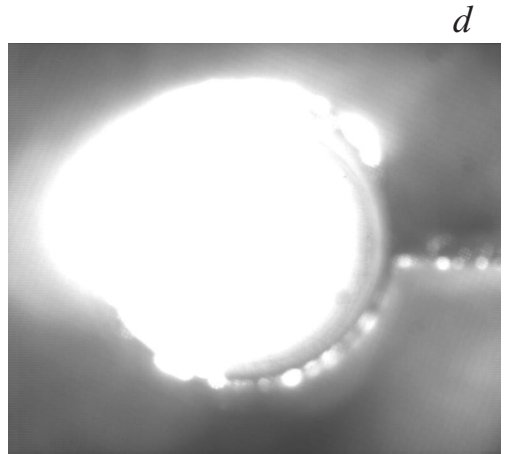

$12.928-13.011 \mathrm{~ms}$

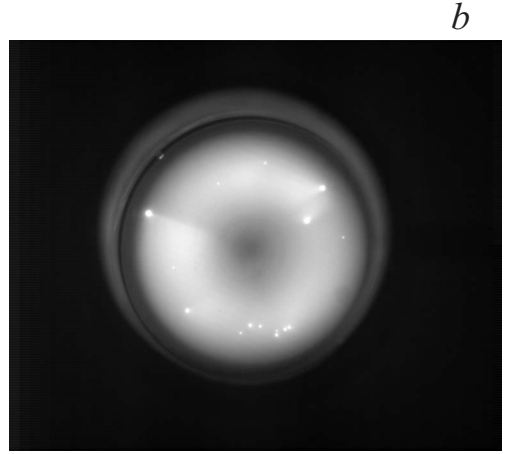

$10.334-10.417 \mathrm{~ms}$

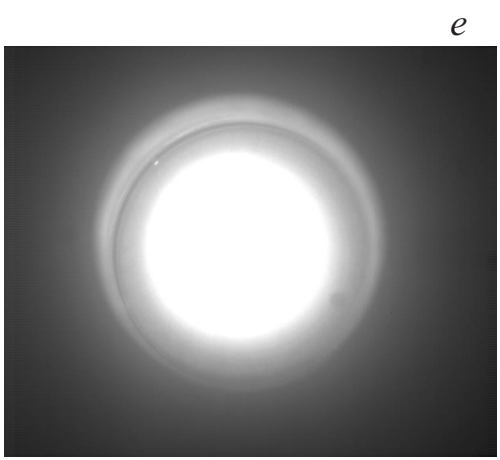

$13.168-13.251 \mathrm{~ms}$

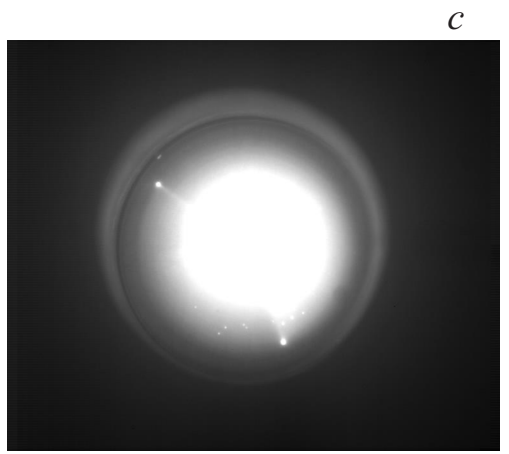

$12.668-12.751 \mathrm{~ms}$

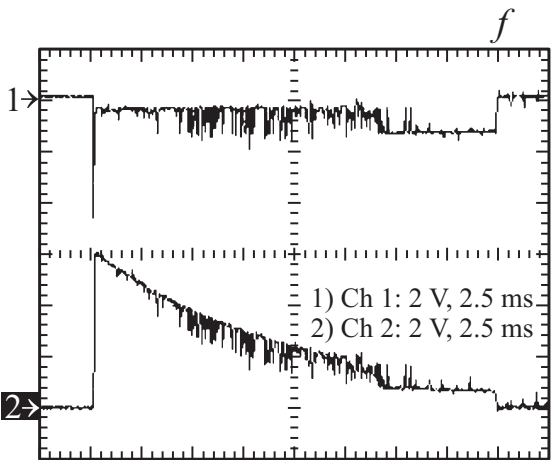

Рис. 7. Кадры видеосъемки $(a)-(e)$ и соответствующие осциллограммы $(f)$ напряжения горения разряда $(\mathrm{Ch} 1,400 \mathrm{~V} / \mathrm{div})$ и полного тока БПМ (Ch2, $2 \mathrm{~A} / \mathrm{div}) ;$ горизонтальная шкала $2.5 \mathrm{~ms} / \mathrm{div}$. Давление аргона $0.067 \mathrm{~Pa}$, зарядное напряжение БПМ $3 \mathrm{kV}$. Задержка запуска соленоида относительно запуска БПМ $12 \mathrm{~ms}$. Задержка запуска БПР относительно запуска БПМ $13 \mathrm{ms.}$

\subsection{4. Наложение ведущего магнитного поля и включение пеннинговского разряда}

Наложение импульсного ведущего магнитного поля, создаваемого соленоидом 4 (рис. 1), существенно меняет наблюдаемую картину (рис. 7). Включение соленоида до появления свечения на плоскости катода приводит, как правило, к погасанию разряда, поскольку нарушаются условия замкнутого дрейфа электронов. Напротив, включение соленоида после появления свечения на плоскости катода приводит к развитию разряда в продольном направлении (рис. 7,c).

При зажигании ОР интенсивность свечения резко увеличивается (рис. $7, d$ ), поскольку ток ОР значительно больше тока МР. После окончания импульса тока ОР свечение некоторое время $(1-1.5 \mathrm{~ms})$ остается достаточно ярким (рис. $7, e)$ и однородным.

\section{3. Измерения коллекторного тока}

На рис. 8 приведены характерные осциллограммы импульсов напряжения горения МР, полного тока БПМ и тока на коллектор. При переходе разряда в низковольтную стадию на коллекторе появляется небольшой ток (не более $0.5 \mathrm{~A}$ ). При отсутствии магнитного поля этот ток сначала уменьшается, а затем (в данном случае через $\approx 7 \mathrm{~ms}$ с момента перехода разряда в низковольтную стадию, рис. $8, a)$ резко возрастает. При наложении продольного магнитного поля ток на коллектор начинает нарастать буквально через $0.2 \mathrm{~ms}$ после начала тока в соленоиде, т. е. когда индукция продольного магнитного поля достигает примерно $5 \mathrm{mT}$, а до максимума ток на коллектор возрастает за $1-1.2 \mathrm{~ms}$ (рис. $8, b$ ). Стадия с малым током, как на рис. $8, a$, почти не видна, поскольку переход МР в низковольтную стадию в данном случае совпал с началом импульса тока в соленоиде.

Парадоксально, но уменьшение зарядного напряжения БПМ с 3 до $2 \mathrm{kV}$ приводило к уменьшению длительности высоковольтной стадии МР.

\section{3. Обсуждение результатов}

Появление свечения у боковой поверхности катода (т.е. в радиальном зазоре) оказалось для нас некоторым сюрпризом. И хотя затем разряд зажигается и на торцевой поверхности катода, утечки в радиальном направлении являются дестабилизирующим фактором для последующего формирования НСЭП. Для понимания создавшейся ситуации и поиска путей подавления радиальных утечек тока проделаем некоторые простые оценки.

Необходимым условием зажигания разряда низкого давления в скрещенных $\mathbf{E} \times \mathbf{H}$ полях является набор электроном на высоте арки циклоиды кинетической энергии, достаточной для ионизации. Кроме того, вы- 

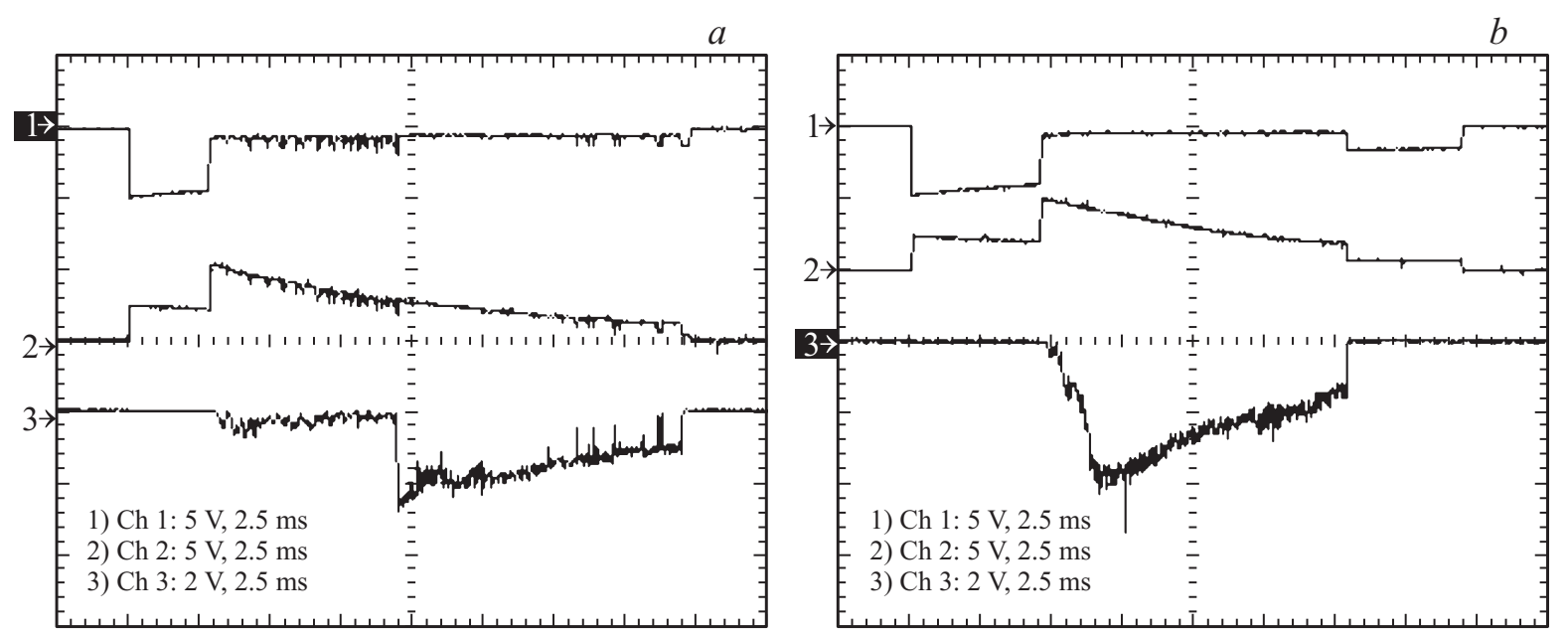

Рис. 8. Осциллограммы напряжения горения разряда $(\mathrm{Ch} 1,2000 \mathrm{~V} / \mathrm{div})$, полного тока БПМ (Ch2, $5 \mathrm{~A} / \mathrm{div})$ и тока на коллектор (Ch3, $2 \mathrm{~A} / \mathrm{div})$; горизонтальная шкала $2.5 \mathrm{~ms} / \mathrm{div} . \quad a-$ без запуска соленоида, $b-$ задержка начала тока соленоида относительно запуска БПМ $5 \mathrm{~ms}$. Расстояние между катодом и коллектором $20 \mathrm{~cm}$. Катод с проволочными эмиттерами с шагом между ними $5 \mathrm{~mm}$. Давление аргона $0.067 \mathrm{~Pa}$, зарядное напряжение БПМ $3 \mathrm{kV}$.

сота арки циклоиды $h=2 m E / e B^{2}[17]$ должна быть меньше межэлектродного зазора ( $m$ и $e-$ масса и заряд электрона соответственно, $E-$ напряженность электрического поля, $B-$ индукция магнитного поля). Положим для определенности, что разность потенциалов на высоте арки циклоиды $U=E \times h=30 \mathrm{~V}$. Тогда при характерных для нашего случая значениях $E \approx 3.4 \times 10^{4} \mathrm{~V} / \mathrm{m}$ индукция магнитного поля не должна превышать $B_{\text {cr }}=(2 m / e U)^{1 / 2} E \approx 0.021 \mathrm{~T}$. Высота арки циклоиды составит при этом $h \approx 0.9 \mathrm{~mm}$. Обратившись к результатам расчетов радиальной и аксиальной компонент магнитного поля (рис. 4), увидим, что площадь поверхности, где выполняется этот критерий, в несколько раз выше в радиальном зазоре, нежели в аксиальном. Другими словами, у боковой поверхности катода имеются более подходящие условия для зажигания разряда. Этим можно объяснить то, что МР начинается вблизи боковой поверхности катода.

Отметим, что в стандартной конструкции магнетрона радиальный зазор составляет обычно $1-2 \mathrm{~mm}$, что намного меньше высоты арки циклоиды (радиальная компонента электрического поля при таком зазоре составляет уже около $\left.10^{6} \mathrm{~V} / \mathrm{m}\right)$, и азимутальный дрейф в этой области становится невозможным, поскольку электроны уходят на заземленную стенку, которая является для МР анодом. В нашем случае, когда заземленная стенка не может находиться столь близко к катоду, подавление развития разряда в радиальном направлении можно осуществить с помощью магнитных или электростатических экранов под плавающим потенциалом, что предполагается реализовать в дальнейшем.

Принципиально важным является наблюдавшееся видеокамерой переключение МР в сторону коллектора при наложении магнитного поля соленоида. В результате такого переключения разряд переходит в иную форму: „прямой разряд“ в продольном магнитном поле (или без него). Это переключение подтвердилось также путем регистрации тока амплитудой до $4 \mathrm{~A}$ на коллектор (рис. 8). Данное переключение открывает возможность формирования плазменного анода необходимой концентрации (около $3 \times 10^{12} \mathrm{~cm}^{-3}$ ) путем ионизации рабочего газа электронами, эмитируемыми плазмой МР. Скорее всего, ток МР целесообразно увеличить в десятки раз. Реализация подобного варианта формирования плазменного анода сулит преимущества перед традиционным способом на основе ОР, поскольку позволит избежать появления плазмы между катодом и стенкой пушки из-за паразитного магнетронного разряда между ней и анодом ОР, неизменно сопутствующего этому способу [18]. И, как следствие, появится возможность увеличения эффективности передачи энергии, запасенной в генераторе высоковольтных импульсов, в энергию пучка, которая сейчас не превышает, как правило, $30-35 \%[3,9,18]$.

Ухудшение стабильности перехода МР на торцевую поверхность катода при уменьшении межцентрового расстояния между эмиттерами с 5 до $3 \mathrm{~mm}$ обусловлено, на наш взгляд, ухудшением условий для азимутального дрейфа электронов, вынужденных „пробираться“ через более плотный частокол эмиттеров.

\section{Заключение}

С помощью скоростной видеосъемки исследована динамика свечения импульсного магнетронного разряда в сильноточной электронной пушке, в которой во взрывоэмиссионный многоэмиттерный катод встроен планарный магнетрон. Установлено, что свечение вначале появляется в радиальном зазоре между боковой поверхностью катода и стенкой корпуса пушки, и лишь через несколько миллисекунд свечение появляется на торцевой (рабочей) поверхности взрывоэмиссионного 
катода. Эксперименты показали возможность достаточно стабильного зажигания разряда при сравнительно низких давлениях аргона (0.067-0.093 Рa), необходимых для работы электронной пушки.

Наложение продольного магнитного поля, необходимого для последующего зажигания отражательного разряда и транспортировки сильноточного электронного пучка, после появления плазмы у торцевой поверхности взрывоэмиссионного катода приводит к переключению разряда в продольном направлении - в сторону коллектора пучка. Данное переключение открывает возможность формирования плазменного анода исключительно с помощью магнетронного разряда, т.е. без использования отражательного разряда.

Конструкция взрывоэмиссионного катода (расстояние между эмиттерами, их высота и т.д.) должна обеспечивать эффективный для ионизации рабочего газа азимутальный дрейф электронов.

Дальнейшие исследования предполагается посвятить предотвращению образования плазмы у боковой поверхности катода. Это позволит, в конечном счете, повысить стабильность образования плазмы на рабочей (торцевой) поверхности катода и увеличить эффективность генерации пучка.

Работа выполнена при поддержке РФФИ (грант № 16-48-700239-р_сибирь-а) и РНФ (грант № 15-13-00023 от 18.05.2015).

Авторы признательны также проф. А.С. Матвееву (Томский политехнический университет) за предоставление видеокамеры и полезные советы по проведению скоростной видеосъемки.

\section{Список литературы}

[1] Proskurovsky D.I., Ivanov Yu.F., Rotshtein V.P. et al // J. Vacuum Sci. Technol. 1998. Vol. A16(4). P. 2480-2488.

[2] Uno Y., Okada A., Uemura K. et al // Precision Engineering. 2005. Vol. 29. P. 449-455.

[3] Ozur G.E., Proskurovsky D.I., Rotshtein V.P., Markov A.B. // Laser Particle Beams. 2003. Vol. 21. P. 157-174.

[4] Dian Luo, Guangze Tang, Xinxin Ma, Le Gu, Liqin Wang, Tingbao Wu, Fang Ma. // Vacuum. 2017. Vol. 136. P. $121-128$.

[5] Лоусон Джс.Д. Физика пучков заряженных частиц. Пер. с англ. М.: Мир, 1980. 438 с.

[6] Рухадзе А.А., Богданкевич Л.С., Росинский С.Е., Рухлин В.Г. Физика сильноточных релятивистских электронных пучков. М.: Атомиздат, 1980. 168 с.

[7] Диденко А.Н., Григорьев В.П., Усов Ю.П. Мощные электронные пучки и их применение. М.: Атомиздат, 1977. $277 \mathrm{c}$.

[8] Назаров Д.С., Озур Г.Е., Проскуровский Д.И. // ПТЭ. 1996. Вып. 4. С. 83-88.

[9] Озур Г.Е., Проскуровский Д.И., Карлик К.В. // ПТЭ. 2005. Вып. 6. C. 58-65.

[10] Озур Г.Е., Батраков А.В., Карлик К.В., Зюлькова Л.А. // Известия вузов. Физика. 2013. Т. 56. Вып. 7/2. С. 37-41.
[11] Кизириди П.П., Озур Г.Е. // ЖТФ. 2015. Т. 85. Вып. 6. C. $132-136$.

[12] Meisner L.L., Markov A.B., Proskurovsky D.I., Rotshtein V.P., Ozur G.E., Meisner S.N., Yakovlev E.V., Poletika T.M., Girsova S.L., Semin V.O. // Surf. Coating. Technol. 2016. Vol. 302. P. 495-506.

[13] Kiziridi P.P., Ozur G.E. // Proc. $19^{\text {th }}$ Int. Symp. on HighCurrent Electronics, Tomsk, Russia, October 2-7, 2016 (to be published in a special issue of the journal „Vacuum“ in 2017).

[14] Кузьмичёв А.И. Магнетронные распылительные системы. Книга 1: Введение в физику и технику магнетронного распыления. Киев: Аверс, 2008. 244 с.

[15] Nikolaev A.G., Oks E.M., Vizir A.V., Yushkov G.Yu., Frolova V.P. // Rev. Sci. Instr. 2016. Vol. 87. N 2. 02A902.

[16] Вересов Л.П., Вересов О.Л. // ЖТФ. 2016. Т. 86. Вып. 1. C. 61-69.

[17] Арцимович Л.А., Лукьянов С.Ю. Движение заряженных частиц в электрических и магнитных полях. М.: Наука: Гл. ред. физ. мат. лит., 1972. 224 с.

[18] Ozur G.E., Popov S.A., Lazutkin M.N. // Proc. of the $13^{\text {th }}$ Symposium on High Current Electronics. Tomsk, Russia, July 25-29, 2004. P. 60-63. 